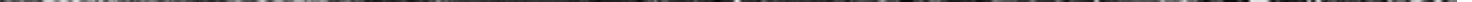

\title{
ACRE PARK PROGRAM IN MANHATTAN
}

El 2011 es celebraven els 200 anys de l'aprovació del Pla dels Commissioners per Manhattan de 1811. La Architectural League of New York i el Museum of the city of New York va organitzar un concurs d'idees anomenat "The Greatest Grid: Call for Ideas" sobre la trama de Manhattan. El concurs anava adreçat a arquitectes, paisatgistes, especialistes en disseny urbà i altres professionals del projecte i el disseny. El contingut era completament lliure i només es demanaven dos panells en format electrònic de $60 \times 90 \mathrm{~cm}$. Van participar 120 projectes de 22 països. El desembre de 2011 es va inaugurar una exposició "The Unfinished Grid: Design Speculations for Manhattan" amb els vuit projectes guanyadors ${ }^{1}$

A continuació es presenta la proposta del grup de professors i investigadors format per Miquel Corominas Ayala, Jordi Franquesa Sánchez, Joan Moreno Sanz y Laia Vilaubí Janer.

\section{La ciutat industrial i la forma urbana}

La forma urbana més representativa de la ciutat industrial és sense cap mena de dubte l'Eixample. Els dos grans eixamples de la ciutat industrial són el Pla dels Comissionats de Manhattan de 1811 i el Pla d'Eixample de Barcelona de I. Cerdà de 1859. Desprès d'anys d'oblit o de poca consideració, l'Eixample de Barcelona ha tingut una tímida reivindicació des de 1959, 1976 i sobretot el 2009 amb motiu de la celebració del 150 aniversari de l'aprovació del Pla, que es va commemorar amb sis importants exposicions a la ciutat. El Pla de Manhattan encara no ha tingut el reconeixement que es mereix. Esperem que aquest 200 aniversari situï aquesta peça en el lloc que li correspon. S'ha de dir que amb una presència modesta el Pla de Manhattan surt de passada en molts treballs i llibres sobre la ciutat. El propi I. Cerdà l'esmenta, el reprodueix i fins i tot analitza els seus paràmetres principals a la memòria del Pla de Barcelona.

Web: archleague.org. Projectes ganadors: The Informal Grid (Isaiah King, Ryan Neiheiser, Giancarlo Valle), The Plaid (Architecture Commons: Eric Ho, Rick Lam), Tabula Fluxus (Group Han Associates New York: Myung Kweon Park, Yikyu Choe, Michael Chaveriat), Flow My Tears, The Commissioners Said (Ghilardi H Hellsten Arkitekter: Franco Krimizi, assisted byYubi Park, Jennifer Endozo Inti Rojanasopondist and Pauline Caubel). NYC City2 (Fotis Sagonas loannis Oikonomou), Dissociative New York (Joshua Mackley, Mathew Ford), Projective Exceptions (Grant Alford, assisted by Spencer Lindstrom. 

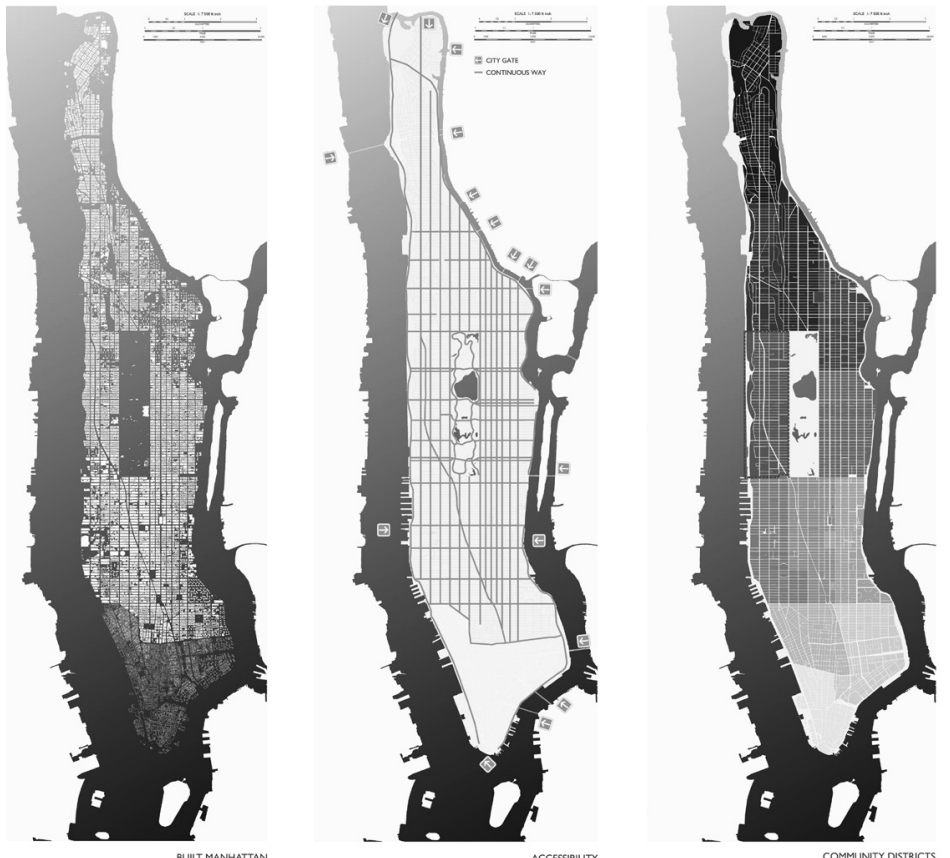

Manhattan: mancanes i espais pùblics, vies principals i el West Side.

\section{Quadrícules i Eixamples}

La diferència entre el teixit resultant de les quadrícules i les malles o eixamples és la diferent proporció que els diferents teixits dediquen als carrers. Mentre que a les quadrícules l'espai destinat a l'accés ocupa una proporció baixa (10-15\% del sòl) a les malles o eixamples la proporció és força més alta (30-35\% del sòl), 32-34\% en el cas de Manhattan. En el procés de modernització de les ciutats amb quadrícules s'han produït dos tipus d'intervenció: Eixamplament dels carrers (Buenos Aires entre altres) o fragmentació d'illes de dimensions desproporcionades (Philadelphia entre altres). Les ciutats amb trames d'eixample del XIX no han hagut de realitzar intervencions radicals sobre els carrers o les illes.

\section{Equilibri residència trebal}

Un dels factors importants de qualitat de les ciutats actuals és l'equilibri entre l'ús residencial i l'espai de treball en el centre de les ciutats. El model de centre terciari envoltat d'àrees residencials planteja greus problemes de transport,
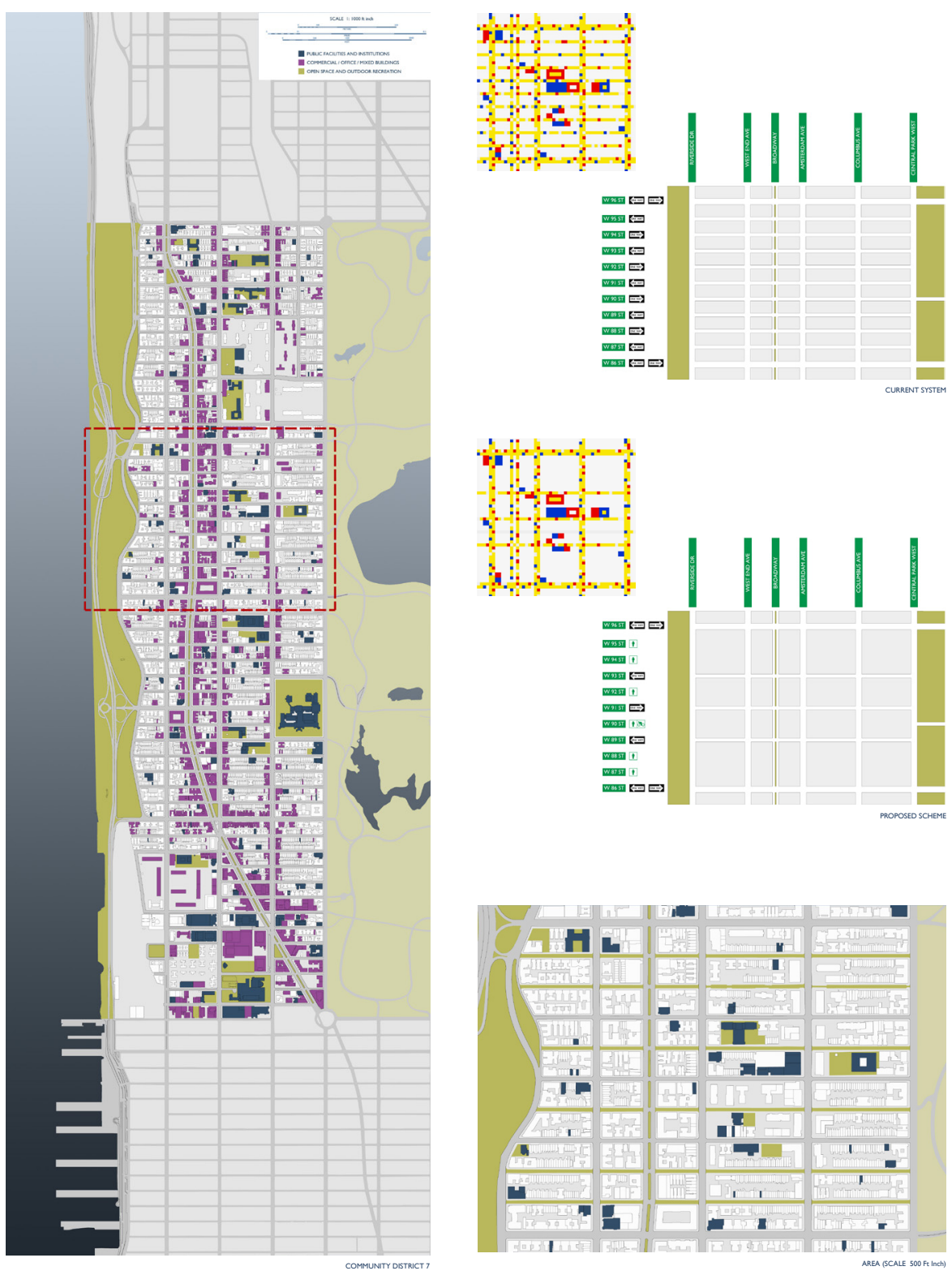

Àmbit de la proposta. Estructura viaria i els carrers-parc 


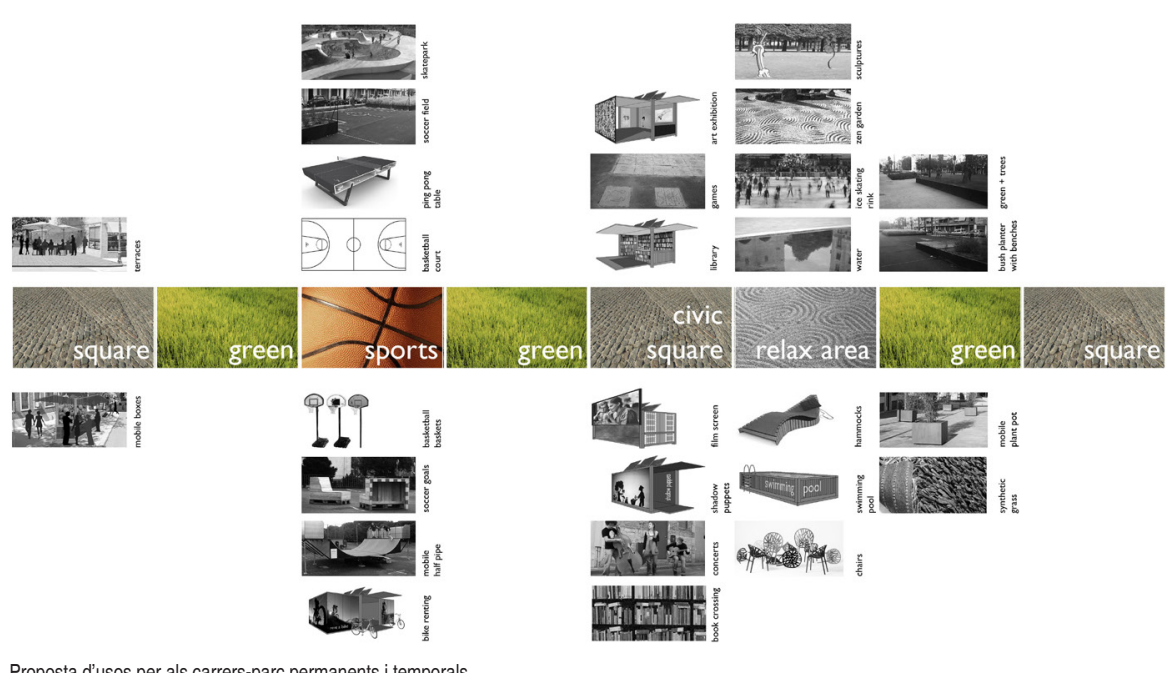

Proposta d'usos per als carrers-parc permanents i temporals.
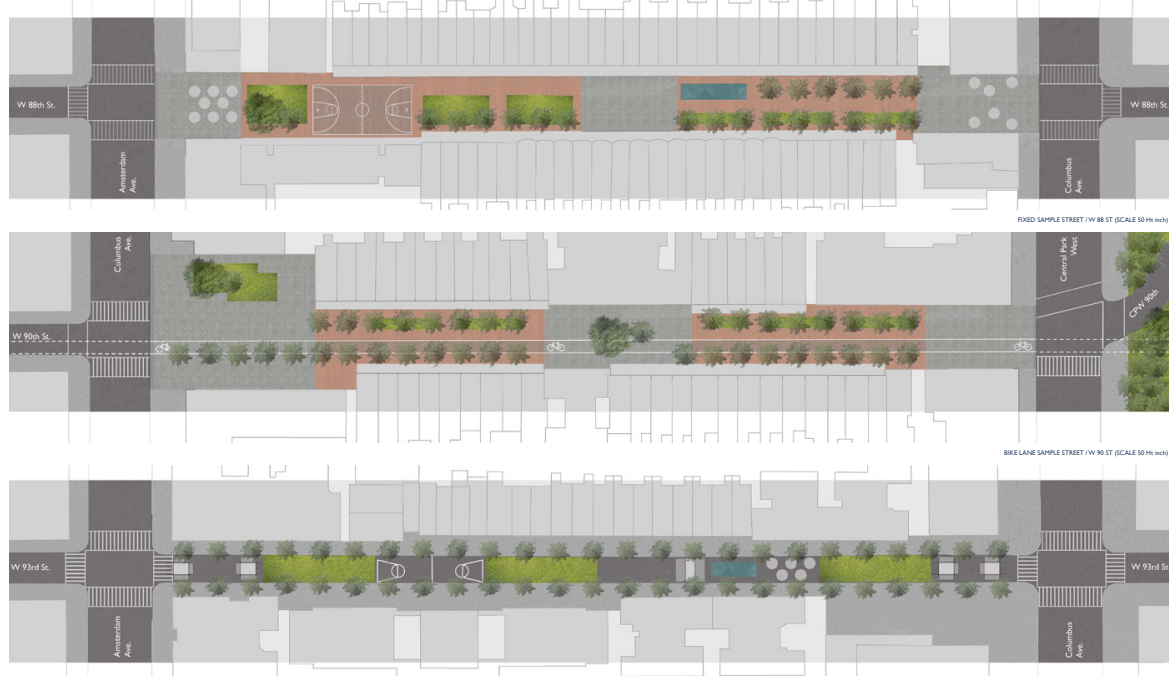

Exemple d'ordenació dels carrers-parc permanents i la implantació del carril bici de qualitat i control social de l'espai. Manhattan n'és un excel-lent exemple, com l'Eixample de Barcelona, d'un espai urbà continu amb una alta intensitat d'edificació, on la residència i el treball tenen una proporció semblant en el conjunt. Aquesta és una qualitat que tenen poques ciutats i que les fa úniques. La identificació de la trama i la ciutat és total. Manhattan és New York i l'Eixample és Barcelona.

\section{El patrimoni dels eixamples}

La construcció d'un eixample com el de Manhattan durant 200 anys amb diferents tipologies arquitectòniques i uns criteris d'urbanització força constants dóna com a resultat un conjunt de gran valor urbanístic on la preservació patrimonial ha d'ésser un objectiu global

\section{Dèficit estructural}

La major part dels eixamples del XIX, i Manhattan no n'és una excepció a pesar de Central Park, tenen una clara manca d'espais lliures públics, de caràcter domèstic principalment, prop de l'habitatge. Manhattan davant d'aquest problema està recuperant els espais perimetrals, antics molls, en contacte amb l'aigua. Tot i això els espais lliures de la ciutat: Central Park, park fluvials i marítims i les places interiors no cobreixen les necessitats de la població.

\section{Opcions de futur per Manhattan}

Una de les opcions, compatible amb moltes altres intervencions, és crear espais públics d'àmbit local.

Queda clar que el manteniment de la proporció entre vials i illes és fonamental i per tant l'opció més lògica per aconseguir nous espais lliures rau en la reinterpretació de l'ús del carrer. Introduint un nivell baix d'especialització en els carrers podem aconseguir un ús de trams de carrers per espai públic. Es tracta d'intervencions que poden ésser inicialment experimentals i finalment fixes. Són en tot cas sempre reversibles i no han de suposar hipoteques definitives per a la ciutat. Per terme mig cada tram de carrer destinat a vianants aportaria un acre d'espai cívic.

\section{Criteris d'especialització del trànsit}

Es proposa un model semblant a l'actual basat en les avingudes en sentit longitudinal i parells de carrers unidireccionals per acollir els dos sentits de circulació en sentit tranversal. Les avingudes no es veurien afectades en la seva secció ni l'ús actual. Tampoc es veurien afectats els grans carrers horitzontals. 

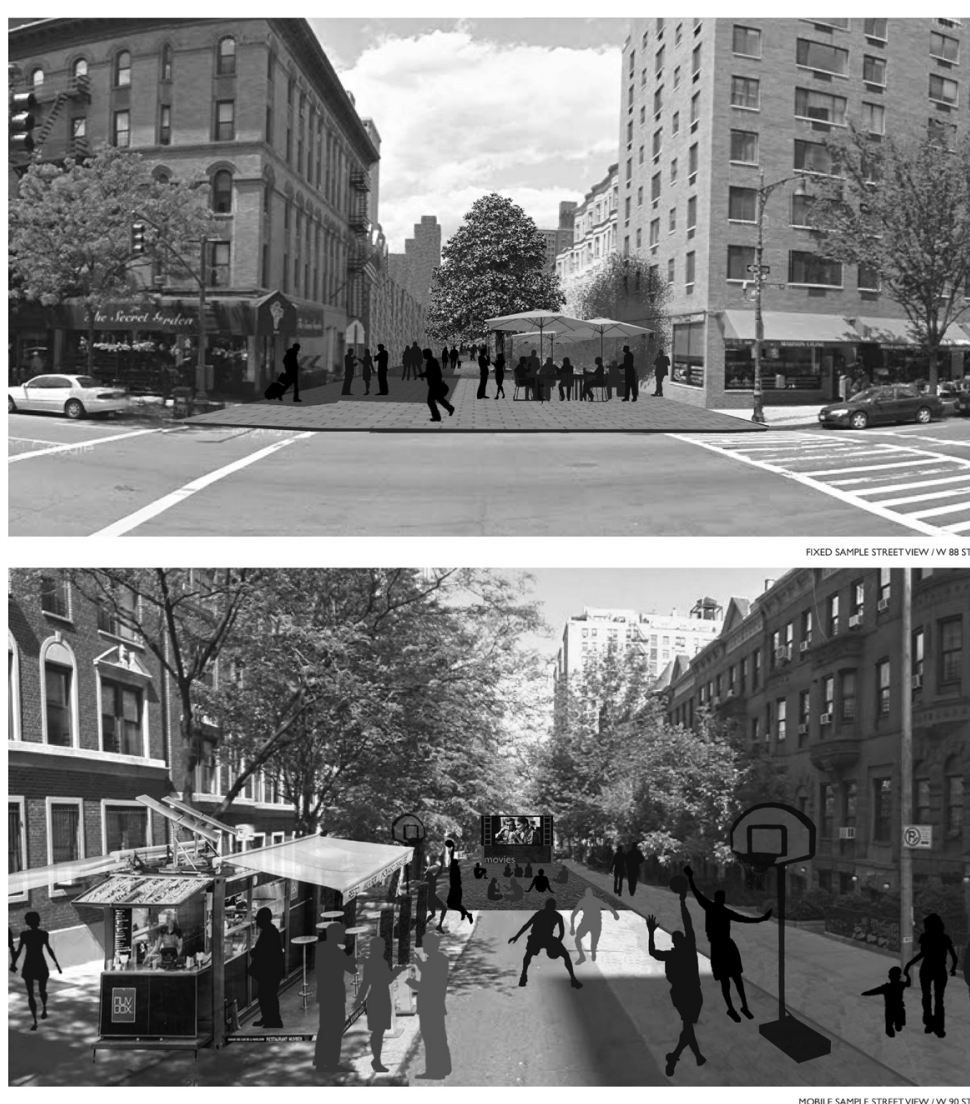

Imatges dels carrers fixes (a la part superior) i carrers mòbils (a la part inferior).

Només es veurien afectats alguns carrers de $60^{\prime}$ que es destinarien a espai per a vianants mantenint els accessos als aparcaments existents en els edificis o per serveis d'escombreries, incendis...Aquest model només es proposa en carrers que no tinguin accés directe a parcs i places perimetrals o que no formin part del sistema de circulació bàsica proposat. La implantació de zones per a vianants també pot ésser temporal en alguns trams i aleshores es proposa un sistema d'elements urbans mòbils. Pot haver intervencions permanents, altres d'estiu, altres de tarda o vespre, altres puntuals...

Aquesta intervenció de zones de vianants parcial pot general un espai del voltant de $4.459 \mathrm{~m}^{2}$ ( 1 acre) entre dues illes de 800" de llargada. Les zones per a vianants d'un tram de carrer ha de permetre destinar el carrer en la totalitat o en part a usos cívics, esportius, culturals...La transformació en zona de vianants d'un carrer sencer ha de permetre sistematitzar parks sense continuïtat física en l'actualitat.
Tot i que hi han diferents llargades en les illes, el lema de la intervenció urbana a Manhattan podria ésser "Acre-Park program".

Lúnic element a resoldre és la relocalització de l’aparcament permanent de residents en els carrers a transformar.

Per experimentar s'ha escollit la zona del Upper West Side de Manhattan, però la metodologia es podria estendre a tot Manhattan. 